\title{
Qualitative Risk of Gas Pipelines
}

\section{Huseyin Murat Cekirge}

Department of Mechanical Engineering, Prince Mohamed Bin Fahd University, Al Khobar, KSA

\section{Email address:}

hmcekirge@usa.net

\section{To cite this article:}

Huseyin Murat Cekirge. Qualitative Risk of Gas Pipelines. American Journal of Energy Engineering. Vol. 3, No.3, 2015, pp. 53-56. doi: 10.11648/j.ajee.20150303.14

\begin{abstract}
A qualitative analysis for determining axis of a gas pipeline in view of general risk is outlined in the paper. The increasing building of gas pipelines for energy transportation vehicle, the importance of risk associated to this transport is gained strong importance. Risk assessment is an extremely useful tool in providing a framework in which to identify the possible hazards and determine the risks associated with gas pipelines. The determination of route, thickness, diameter and segment lengths is the major factor of constructing gas pipelines. The paper is presenting this risk in general and in a qualitative manner.
\end{abstract}

Keywords: Gas Pipelines, Quantitative Risk Analysis, Quantitative Risk Assessment, Fire Gas Pipelines, Explosion Gas Pipelines, Toxication Gas Pipelines, Gas Pipeline Segments

\section{Introduction}

For securing energy sources in view of changing political situations, new gas pipelines will be constructed from production areas to the consumption zones.

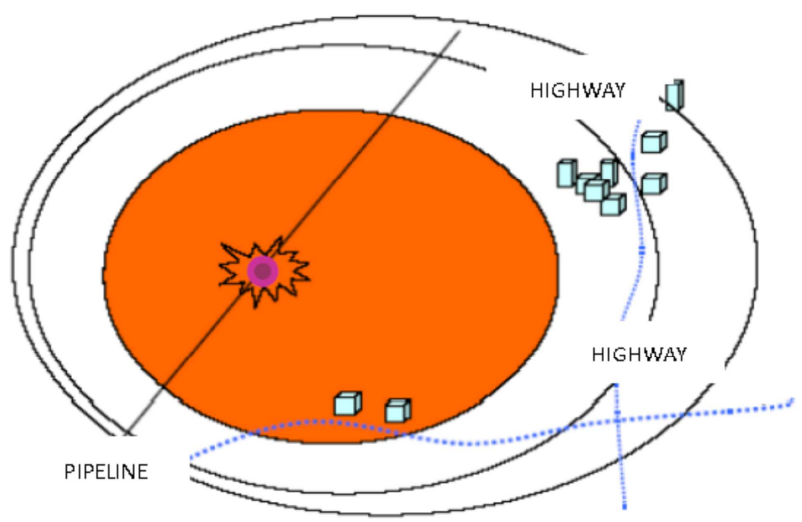

Figure 1. The danger zone, [1].

One of the major difficulties of building these pipelines is overcoming of risk problems on environment where the pipelines are built, [2-6]. Emergency response plan and risk analysis must be prepared for the pipeline's building and operation. These plans must cover environmental compliance of the gas pipeline, investigation of gas pipeline's socioeconomic aspects and prevention of all problems during operation and minimization of their effects calculation of risk factors.

Calculation of risk or risk assessment consists of technical and environmental specifications and must include the risk factors originated from environmental events and operational activities. The risk factors must be in suitable details and risk probability must be in calculation basis, reasonable, regular and documentable.

The operational risks are pipe age, terrestrial location of the pipeline, precautions against corrosion, periodic maintenance, supervision of the line and other factors. Operational risks that might be caused by leakage are fire (pool, jet and flare up), gas distribution (concentration), explosion and toxicity. It is necessary to define the danger zone for determination of payable losses and compensations, see Figure 1. Figure 2 and 3 present the movement of the plume from the gas pipeline. In Figures 4, 5 and 6, the influence zones are presented, [7 - 11].

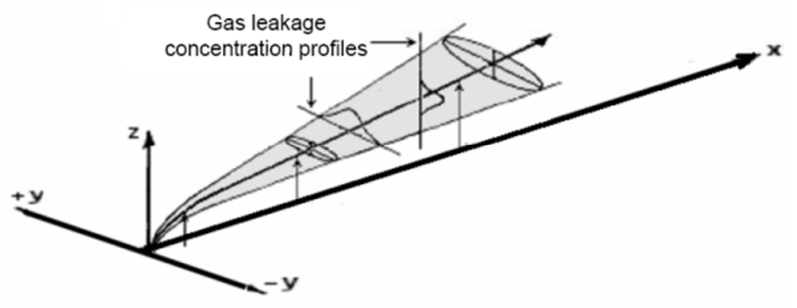

Figure 2. Gas plume from the pipeline, [11]. 


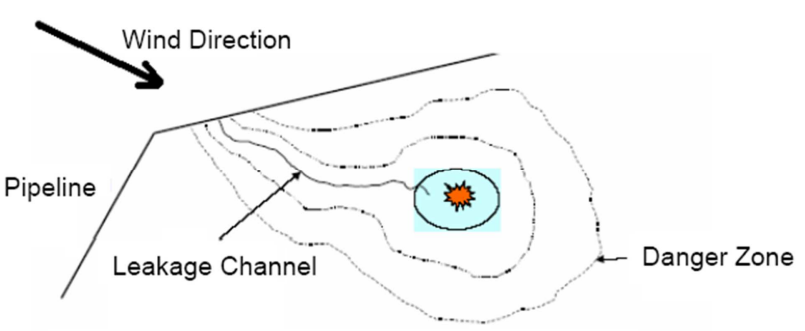

Figure 3. Effects of meteorology and topography on gas plume, [1].

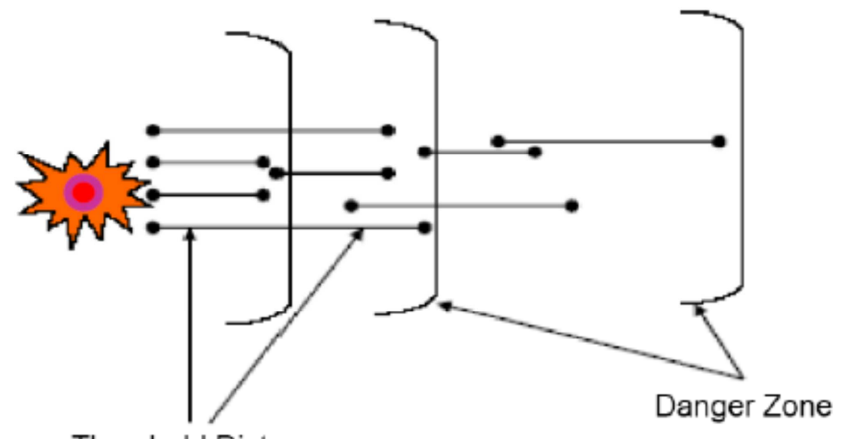

Threshold Distance

Figure 4. Influence zone and various distances of gas leakage, [1].

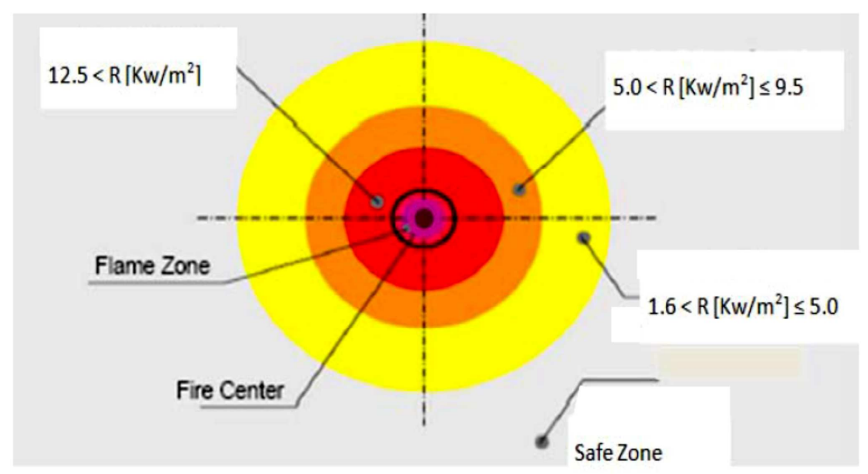

Figure 5. Impact areas for fire, [1].

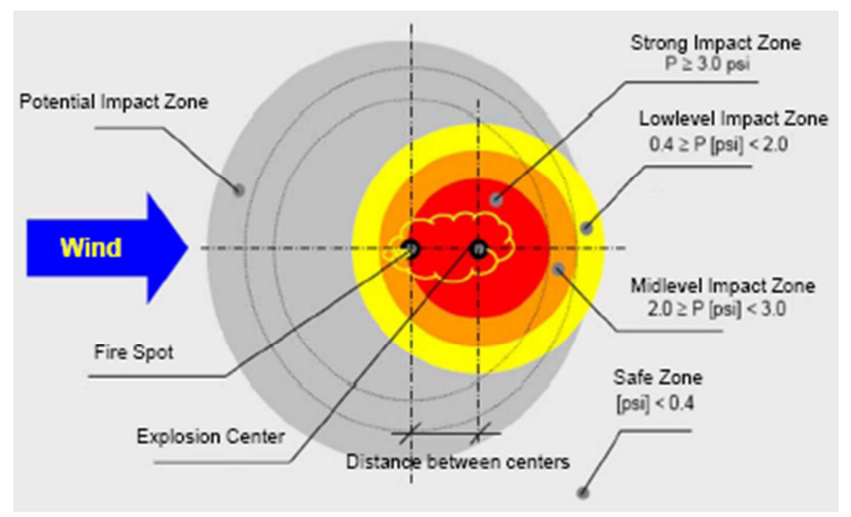

Figure 6. Impact areas for explosion, [1].

The receptors must include count and type; and these receptors must be quantified in units. A unit can be assigned a fixed money value and that simplifies remediation or compensation to injured values.

\section{Risk Analysis of Hazardous Events}

The environmental risks are affected be terrestrial location of the pipeline, settlements, flora and animals, agriculture and livestock, terrorism and other factors, [11-18],

Basic principlesof calculations are

- Calculate on every point

- Comparison of segment lengths

- Hazards

- Calculation of all collapse factors for pipeline

- Calculation of thickness in terms of time factor

- addition of all risks

The risk assessment factors are pipe age, the land on which the pipeline is placed, precautions against corrosion, position of settlements near the pipeline and others factors. Indexing methods is used to quantify the risk.

Risk assessment results determination of pipeline route, calculation of pipe segments' length, calculation of pipe diameter and thickness and other details. The foresights for risk analysis are conervative calculations, uncertain details, past events, expert assessments, relative assessments, scenarioassessments, probabilistic assessments

Determination risk term by using absolute results or relative result's model.The models should contain in, probabilistic methods, scenarios, trees, results and verification, and determination of formation frequency

Basic risk scenarios are leakage jet (pool) fire, tear jet (pool) fire, leakage flare fire, tear flare fire, leakage explosion, tear explosion, underground leakages in embedded pipes If sea passages are considered the toxicity of beam risingin the sea and its effects, the effects of sea water's density change, especially on surface.

The pipeline risk analysis factors are size, age, type and operating pressure of the pipeline, product transported and location of the line, relative to natural and man-made threats. Consequences of of gas release are proximity of the line, meteorological and topographical conditions, local terrain and land use. The qualitative methods are improved to quantitative methods.

The general steps in a pipeline risk analysis are as follows:

Data Compilation - The first step is to compile all pertinent data for the risk analysis. This includes the location and characteristics of the pipeline and the area site of interest.

Hazard identification - The pipeline system must be characterized in sufficient detail to formulate potential accident scenarios and to pen-lit subsequent evaluation of accident probability, likely release amount and nature and magnitude of resulting impacts:

Probability analysis - Probability analysis determines the likelihood of an event expressed in relative (typically referred to as likelihood) or quantitative teens (typically referred to as probability).

Consequence analysis - Consequence analysis examines the potential physical impacts and derivative consequences (e.g. harm to people. or the environment) of a pipeline failure and accidental release of product.

Risk evaluation - Risk evaluation creates a numerical 
combination of both the probability of all and its consequences.

Risk control - Risk control consists of prevention and mitigation measures respectively to reduce the probability that a release of pipeline product will occur and to minimize the impacts of any release that might occur.

Reporting - When the risk analysis is completed and results are reported to management. The report contains information on the area pipeline, method, data and assumptions and results.

The causes of pipeline failure are corrosion (internal and external), excavation damage, natural forces ground movement, flooding, and displacement, etc.), other outside forces (e.g. fire or explosion near the pipeline); material and weld defects, equipment and operations (e.g. such as over pressuring and an inadequately protected system through inappropriate operating settings); and other (i.e. not included above or unknown).

Risk Control can be done through prevention and mitigation. Prevention measures are used to control risk by reducing the likelihood of a risk event occurring. Traditionally; codes, standards, regulations and an operator's own good practices comprise prevention activities. Specific prevention activities generally focus on specific causes of pipeline failures For example, prevention measures associated with excavation damage including pipeline makers, patrols, and one-call notifications. Mitigation measures are pre-engineered systems. Procedures and practices that reduce the consequences of a pipeline product release, should a release occur. Emergency preparedness and emergency response plans are one of the most basic elements of mitigation. Some mitigation measures are common to all pipelines; some depend on whether the line is a gas or liquid pipeline and whether the issue is product flammability, toxicity or both. Risk analysis has three stages; these are risk screening, qualitative and detailed qualitative analysis.

For a given length of pipeline within $\mathrm{X}$ of a site property line, each of these hazards has a unique length of pipe from which the impacts could reach a receptor. Outside of this length the impacts could not reach the receptor. The segment length for which a hazard can have an impact is the length XSEG; the hazard impact distance and XSEG, see Figure 7.

The steps of an analysis, in sequence, to determine the hazard impact distance XSEG length for each of the, three hazard types based on the distance between the receptor and the pipeline hazard source, and the hazard impact distance which is maximum mortality impact from the closest approach of the pipeline to the receptor.

- Average mortality at the receptor for each XSEG.

- Base adjusted failure probability for the pipeline.

- Base probability for each XSEG.

- Conditional probability factor for each event scenario

- Conditional probability of individual exposure.

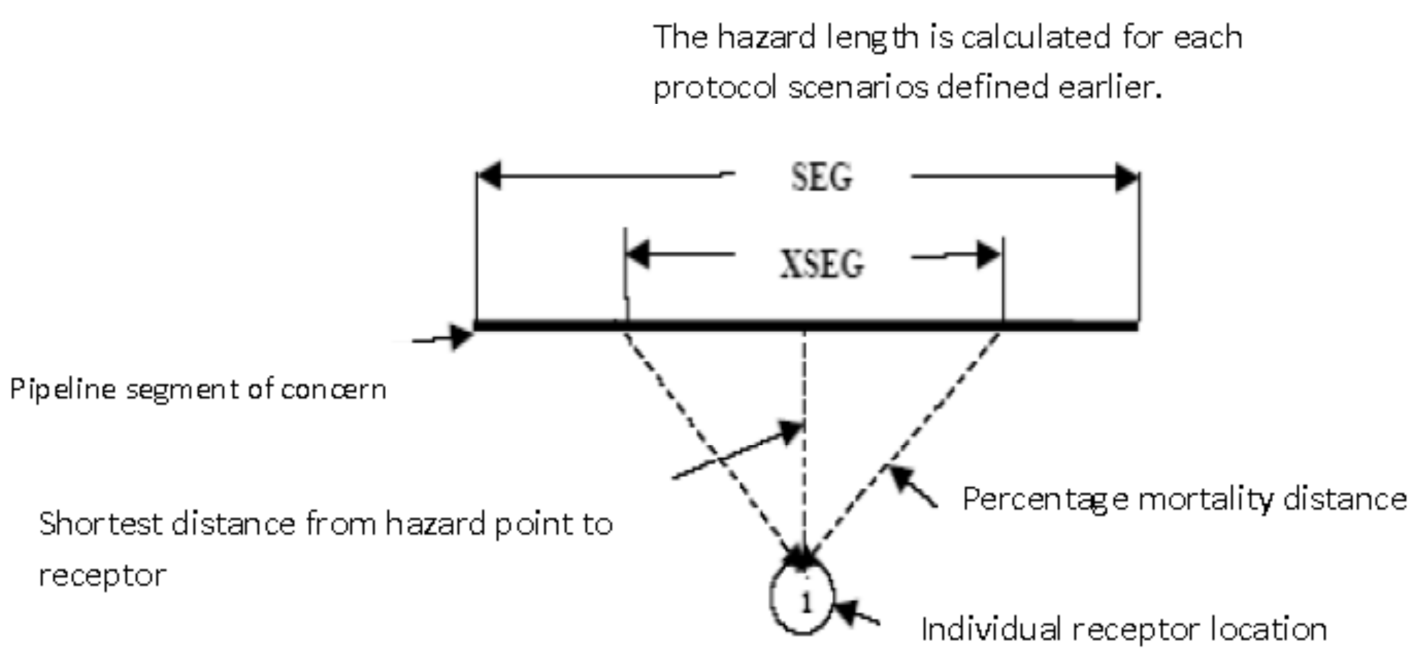

Figure 7. Segment and safety XSEG, [1].

\section{Discussion}

The complications and detail of risk analysis of a gas pipeline is introduced. The fire, explosion and toxicity are main issues for a building and operating a gas pipeline. Importance of selection of segment length is the important part of the designing a gas pipeline. The paper is the guidance will give basic preparation rules of risk analysis of gas pipelines.

\section{Conclusion}

This study of risk of a pipeline transport system activity is presented. Total risks of infrastructures are based on the infrastructure and operation. These quantitative risks are based on threatening consequences of events identified. Quantitative risk assessment has its foundation in the application of procedures used in other transport infrastructure of hydrocarbon sector and industry. By that way, the risk of an infrastructure can be determined in the 
area of tolerable range. In this procedure, spill events must be included that have occurred to date.

In considering risk characteristics of a pipeline transport system and operation, the risk of each infrastructure must be considered. The risks located in acceptable levels are considered tolerable. Acceptable levels of risk are tolerable to the human settlements which fall within the acceptable zones. In the area of human settlements, divulgation of activities and preparation of communities are considered as preventive measures, [19-22].

The ground motions in the integrity of the infrastructure should be monitored by annually scheduled activities and new assessments should be scheduled with idle paths, in which to identify new high sensitivity points for modifying maintenance programs.

\section{References}

[1] H. M. Cekirge, Safety Analysis, Maltepe Uni., Internal Rep. 1/1, Istanbul, 2010.

[2] G. Pluvinage and M. H. Elwany (Editors) Safety, Reliability and Risks Associated with Water, Oil and Gas Pipelines, NATO Science for Peace and Security Series C: Environmental Security, Springer, 2007.

[3] United States Congress Senate, To reduce risk to public safety and the environment associated with pipeline transportation of natural gas and hazardous liquids, and for other purposes, US Congress and Senate, Paperbackshop-US, Secaucus, NJ, 2010.

[4] J.L. Kennedy, Oil and Gas Pipeline Fundamentals, Pinacle Books, Richford, VT, 1984.

[5] Rizkalla, M. (editor), Pipeline Geo-Environmental Design and Geohazard Management, ASME, 2008.

[6] W. K. Muhlbauer, Pipeline Risk Management Manual: Ideas, Techniques, and Resources, Gulf Publishing Services, Burlington, Mass., 2004

[7] GIUSP, The Gas Industry Unsafe Situations ProceduresEdition 6, Including 1 \& 2, 2 April 2012.

[8] Young-Do Jo and Daniel A. Crowl, Individual risk analysis of high-pressure natural gas pipelines, Journal of Loss Prevention in the Process Industries, Volume 21, Issue 6, Pages 589-595, November 2008

[9] IGEM, Institution of Gas Engineers \& Managers, Assessing the risks from high pressure Natural Gas pipelines, IGEM/TD/2 Edition 2, Communication 1764, 2013.
[10] E. W. McAllister, Pipeline Rules of Thumb Handbook, Elsevier Inc., 2005.

[11] U.S. Department of Transportation, Natural Gas Pipeline Systems,(https://primis.phmsa.dot.gov/comm/NaturalGasPipel ineSystems.htm), 2011.

[12] R. Michael Reynolds, ALOHA (Areal Locations of Hazardous Atmospheres) 5.0 Theoretical Description, NOAA Technical Memorandum NOS ORCA-65, Seattle, Washington 98115, August 1992.

[13] Pipeline and Hazardous Materials Safety Adminstration, Gathering Pipelines: Frequently Asked Questions, (http://phmsa.dot.gov/portal/site/PHMSA/menuitem.ebdc7a8a 7e39f2e55cf2031050248a0c/?vgnextoid $=0 \mathrm{a} 69 \mathrm{c} 4 \mathrm{~d} 9 \mathrm{aebb} 6310$ VgnVCM1000001 ecb7898RCRD\&vgnextchannel $=623 \mathrm{~b} 1433$ 89d8c010VgnVCM1000008049a8c0RCRD\&vgnextfmt=print ), 2015.

[14] Government Accountability Office, Pipeline Safety, (http://gao.gov/assets/590/589514.pdf), 2012.

[15] W. E. Baker, P. A. Cox, P. S. Westine, J. J. Kulesz and R. A. Strehlow. Explosion Hazards and Evaluation. Elsevier Scientific Publishing Company, Amsterdam - Oxford - New York, 1983.

[16] M. R. Hankinson, G. Ashworth and B. P. Mohsen Sanai and James D. Colton, "A Full Scale Experimental Study of Fires Following the Rupture of Natural Gas Transmission Lines," ASME Conference Proceedings, 2000.

[17] Design Institute for Physical Property Data (DIPPR), American Institute of Chemical Engineers (AIChE),given in DIPPR computer software, Version March 1995, Technical Database Services, Inc., 1995.

[18] B31.8S 2001, Supplement to B31.8 on Managing System Integrity of Gas Pipelines. ASME International, New York, New York, January 31, 2002, Center for Chemical Process Safety (CCPS), Guidelines for Chemical Transportation, 2002.

[19] Y. D. Jo and D. A. Crowl, Individual Risk Analysis of HighPressure Natural Gaspipelines. Journal of LossPrevention in the Process Industries, 21, 589-595, (http://dx.doi.org/10.1016/j.jlp.2008.04.006), 2008.

[20] D. P. Nolan, Applications of HAZOP and What-If Safety Reviews to the Petroleum, Petrochemical and ChemicalIndustries, Noyes Publications, Saddle River, 7, 1994.

[21] Y. Y. Haimes, Risk Modelling, Assessment, and Management. 3rd Edition, John Wiley \& Sons Inc., Hoboken, 2008.

[22] 7th Report of the European Gas Pipeline Incident Data Group, Gas Pipeline Incidents, December 2008, Document No. EGIG 08 TV-B 0502, 2008. 